\title{
ETNOMATEMATIKA: KONSEP GEOMETRI PADA KERAJINAN TRADISIONAL SASAK DALAM PEMBELAJARAN MATEMATIKA DI SEKOLAH DASAR
}

\author{
Asri Fauzi, Heri Setiawan \\ Universitas Mataram \\ asrifauzi@unram.ac.id, heri_setiawan@unram.ac.id
}

\begin{abstract}
ABSTRAK
Pembelajaran matematika dengan konsep budaya lokal atau yang disebut dengan etnomatematika merupakan suatu strategi untuk mengajarkan siswa sekolah dasar dalam belajar matematika yang selama ini dianggap menakutkan. Tujuan penelitian ini adalah untuk mendeskripsikan konsep-konsep geometri yang terkandung dalam kerajinan tradisional masyarakat Sasak. Dalam penelitian ini, jenis penelitian yang digunakan adalah penelitian kualitatif dengan pendekatan etnografi. Metode yang digunakan untuk memperoleh data yaitu dengan metode studi lapangan yang diberbantukan oleh dua dosen PGSD, eksplorasi, observasi, dan dokumentasi. Instrumen penelitian ini adalah peneliti sendiri yang berperan sebagai instrumen utama. Hasil penelitian ini berupa konsep-konsep matematika khususnya konsep geometri yaitu pada motif kerajina tradisional tenun sesekan Sasak mengandung unsur bangun datar berupa persegi, persegi panjang, layang-layang, jajargenjang, segitiga, belah ketupat, konsep sudut, dan konsep kesebangunan. Kemudian pada kerajinan tradisional nyiru mengandung konsep bangun datar berupa lingkaran, dan elips. Selanjutnya pada kerajinan besek dan tembolaq mengandung konsep geometri berupa bangun ruang yaitu balok, kubus, dan setengah bola. Konsep-konsep geometri yang terdapat pada kerajinan tradisional masyarakat Sasak dapat dimanfaatkan oleh guru dalam pembelajaran matematika sekola dasar dan dapat memupuk rasa cinta siswa terhadap budaya mereka sendiri.
\end{abstract}

Katakunci : Etnomatematika, konsep geometri, kerajinan tradisional Sasak

\section{ABSTRACT}

Mathematics learning with the concept of local culture or what is called ethnomathematics is a strategy to teach elementary school students in learning mathematics which has been considered scary. The purpose of this study is to describe the geometrical concepts contained in the traditional craft of Sasak society. In this study, the type of research used is qualitative research with an ethnographic approach. The method used to obtain data is the field study method which is assisted by two PGSDs lecturers, exploration, observation, and documentation. This research instrument is the researcher himself who acts as the main instrument. The results of this study in the form of mathematical concepts, especially the concept of geometry, namely the traditional handicraft weaving sesekan Sasak contains elements of flat shapes in the form of a square, rectangular, kite, parallelogram, triangles, rhombus, angular concepts, and the concept of congruence. Then in the traditional craft nyiru contains the concept of a flat figure in the form of a circle and ellipse. Furthermore, the craft baskets and Tembolaq contain geometrical concepts in the form of building space, namely blocks, cubes, and half balls. The geometrical concepts found in the traditional craft of Sasak society can be utilized by teachers in learning elementary school mathematics and can foster students' love for their own culture.

Keywords : etnomathemathic, geomatry concept, Sasak's traditional Handycraft 


\section{PENDAHULUAN}

Matematika merupakan salah satu mata pelajaran wajib yang harus diberikan sedini mungkin sejak anakanak mengenal pendidikan baik itu pendidikan formal maupun nonformal. Pemberian pembelajaran matematika kepada anak tentunya akan melatih anak untuk mengembangkan kemampuannya dalam berpikir secara logis, sistematis, dan kreatif. Kemampuankemapuan tersebut termuat dalam Permendiknas Nomor 22 Tahun 2006 yang menyatakan bahwa matematika sekolah akan membekali siswa agar memiliki kemampuan untuk bekerjasama, serta memiliki kemampuan dalam berpikir lebih logis dan analitis.

Lebih lanjut Crawford, Saul, Mathewa, dan Makinster (2005) mengatakan bahwa ada 4 tujuan pelajaran matematika yaitu: "(1) learn mathematics concepts and problemsolving strategies; (2) gain new knowledge through problem solving in authentic contexts; (3) learn in student-directed, experiential, active, and collaborative setting; (4) use inquiry and discovery". Artinya bahwa tujuan pembelajaran matematika yaitu mempelajari konsep matematika dan strategi pemecahan masalah, mendapatkan pengetahuan baru melalui pemecahan masalah dalam konteks yang sebenarnya, belajar dari pengalaman siswa secara langsung dan aktif bekerjasama dengan siswa lainnya, dan yang terakhir menggunakan penyelidikan dan penemuan dalam proses pembelajaran. Untuk mencapai tujuan pembelajaran matematika tersebut, tentunya guru seyogyanya menggunakan berbagai metode dan model pembelajaran yang dianggap efektif baik dari proses belajar mengajar maupun hasil dari proses pembelajaran. Namun fakta dilapangan menunjukkan, tidak sedikit guru yang masih menggunakan metode konvensional seperti ceramah dalam proses pembelajaran matematika. Apabila pembelajaran matematika dilaksanakan dengan metode seperti itu, dimungkinkan siswa sekolah dasar tidak bisa berekplorasi dan mengembangkan kemampuannya dalam berpikir. Hal tersebut dikarenakan dalam proses pembelajaran siswa tidak diajak melakukan suatu penemuanpenemuan untuk memecahkan masalah terkait dengan matematika dalam kehidupan sehari-hari anak.

Salah satu materi yang sangat erat kaitannya dengan kehidupan sehari-hari yaitu geometri. Geometri merupakan salah satu materi pelajaran yang selalu ada pada jenjang pendidikan dari sekolah dasar sampai perguruan tinggi. Di sekolah dasar utamanya, pembelajaran tentang konsep geometri telah dikenalkan kepada siswa kelas rendah. Oleh karena itu untuk menjadikan materi geometri ini lebih menarik, dibutuhkan suatu metode belajar yang berkaitan dengan budaya 
yang sering dijumpai. Metode belajar yang mengaitkan unsur budaya dengan matematika ini disebut dengan Etnomatematika. Sirate (2012) mengatakan bahwa terdapat lima kemungkinan etnomatematika dapat diterapkan yaitu etnomatematika harus dirancang dalam konteks yang sesuai dan berarti, (2) disampaikan dalam bentuk konten atau isi budaya khusus yang berbeda dengan konsep matematika umumnya, (3) konsep berikutnya dalam kurikulum etnomatematika adalah membangun ide bahwa etnomatematika berada pada tahapan pengembanfan pemikiran matematika yang terapkan dalam bidang pendidikan, (4) penerapan kurikulum etnomatematika dapat menjadi bagian ide matematika, (5) kurikulum etnomatematika merupakan integrasi konsep dan praktek matematika ke dalam budaya siswa.

Selanjutnya D'Ambrosio (2001) menjelaskan bahwa tujuan dari etnomatematika adalah untuk memperkenalkan konsep-konsep matematis dengan menghubungkan budaya lokal sebagai media dalam mempelajari matematika. Rosa dan Orey (2011) melakukan suatu penelitian tentang etnomatematika yang bertujuan bagaimana pembelajaran matematika di sekolah lebih mempertimbangkan latar belakang sosial budaya siswanya. Hasil penelitian tersebut menunjukkan bahwa pembelajaran dengan pendekatan etnomatematika membantu siswa mengembangkan kemampuan kognitif, dan emosional siswa dengan memanfaatkan budaya mereka sendiri untuk menghasilkan pengetahuan, keterampilan, dan sikap yang lebih baik.

Ubayanti, Lumbantobing, dan Manurung (2016) mengatakan bahwa matematika bagian dari kebudayaan dan bersifat universal. Hardiarti (2017) mengatakan bahwa pembelajaran dengan objek etnomatematika yang konkret dapat mendukung dan membantu siswa dalam memahami matematika yang sifatnya abstrak. Noto, Firmasari, \& Fatchurohman (2018) mengatakan etnomatematika menjadi salah satu strategi pembelajaran yang baik dalam memahami dan mempelajari matematika sekaligus menumbuhkan rasa cinta siswa terhadap budaya. Oleh karena itu pembelajaran matematika yang berbasis budaya akan lebih menarik sehingga dapat menjadikan siswa lebih aktif dan berfikir kreatif dalam mengeksplorasikan temuannya.

Berbagai penelitian tentang etnomatematika telah dilaksanakan oleh beberapa peneliti. Zayyadi (2017) meneliti tentang etnomatematika pada batik madura. Hasil penelitiannya berupa konsepkonsep geometri terdapat pada motif batik Madura yaitu garis lurus, garis lengkung, garis sejajar, simetri, titik, sudut, persegi panjang, segitiga, lingkaran, jajargenjang, dan 
kesebangunan. Huda (2018) meneliti tentang etnomatematika pada jajanan pasar di daerah Istimewa Yogyakarta dengan hasil penelitian pada jajanan pasar terdapat unsur geometri bentuk bidang datar segi empat, lingkaran, segitiga, trapezium, elips, sedangkan untuk bangun ruang ditemukan bentuk bola, silinder, balok, kerucut. Yazid (2018) dalam penelitiannya tentang eksplorasi etnomatematika masyarakat suku Sasak lombok terhadap penamaan karakter budaya dengan tujuan menanamkan nilai karakter cinta terhadap budaya dan matematika.

Penelitian selanjutnya dari Hardiarti (2017) dalam artikelnya tentang etnomatematika pada Candi Muaro Jambi yang dapat dijadikan sebagai sumber belajar matematika. Hasil penelitiannya menunjukkan bahwa struktur Candi Muaro Jambi berbentuk persegi, persegi panjang, jajargenjang, trapesium, dan segiempat tidak beraturan. Arwanto (2017) mengenai eksplorasi etnomatematika batik Trusmi Cirebon menunjukkan bahwa dalam batik tersebut mengandung unsur-unsur matematis yaitu konsep simetris, transformasi, dan kekongruenan. Penelitian yang dilakukan oleh Laurens (2016) tentang analisis etnomatematika untuk meningkatkan kualitas pembelajaran untuk memahami konsep bilangan, pecahan, dan geometri. Fauzi \& Lu'luilmaknun (2019) dalam penelitiannya terdapat unsur-unsur geometri pada permainan tradisional dengklaq yaitu pada arena permainan terdapat unsur geometri bidang persegi, segitiga, dan setengah lingkaran. Kemudian pada gaco yang digunakan pemain terdapat unsur persegi, persegi panjang, lingkaran, trapesium, segitiga.

Selanjutnya penelitian yang dilakukan oleh Richardo (2016) tentang penerapan etnomatematika dalam pembelajaran matematika pada kurikulum 2013. Hasil penelitiannya menunjukkan bahwa hadirnya etnomatematika dalam pembelajaran matematika memberikan nuansa yang baru bagi siswa bahwa dalam belajar matematika siswa dapat berinteraksi dengan kebudayaan mereka sendiri. Adanya hubungan matematika dengan budaya dapat digunakan menjadi media pembelajaran matematika, sehingga pembelajaran dengan etnomatematika selaras dengan apa yang dituntun dalam kurikulum 2013.

Etnomatematika dalam budaya Sasak termuat dalam beberapa aspek misalnya adat istiadat suku Sasak, artefak, arsitektur atau bentuk banguna tradisional, kesenian, kerajinan, bahkan bentuk makanan tradsional suku Sasak. Fokus kajian etnomatematis dalam penelitian ini yaitu kerajinan tradisional Sasak, Lombok, NTB. Kerajinan tradisional Sasak, secara fisik memiliki corak, motif, dan bentuk geometri. Misalnya pada kain tenun dengan motif 
persegi, lingkaran, segitiga, dan bangun geometri lainnya. Kemudian pada kerajinan anyaman bambu, jika diperhatikan membentuk unsur geometri bidang dan ruang misalnya pada Nyiru (lingkaran), Besek (balok, kubus), dan tembolaq (setengah lingkaran), dan berbagai jenis kerajinan tradisional lainnya. Mendalami beberapa bentuk geometri bidang dan ruang yang terdapat pada kerajinan tradisional Sasak sangat menarik jika dikaitkan dengan pembelajaran matematika SD.

Berdasarkan uraian di atas, maka etnomatematika dapat memberikan kontribusi yang besar untuk kemajuan dalam proses pembelajaran matematika sekolah dasar. Oleh karena itu tujuan dalam penelitian ini untuk mendeskripsikan konsep geometri yang terdapat pada kerajinan tradisional Sasak.

\section{METODE PENELITIAN}

Jenis penelitian ini merupakan penelitian kualitatif dengan pendekatan etnografi. Metode yang digunakan untuk memperoleh data yaitu dengan metode studi lapangan, eksplorasi, observasi, wawancara dan dokumentasi. Pada penelitian ini, terfokus pada kerajinan tradisional suku Sasak, Lombok, Provinsi Nusa Tenggara Barat (NTB), dan melibatkan dua orang dosen PGSD sebagai informan untuk membantu peneliti dalam mengeksplorasi unsur-unsur geometri yang ditemukan pada kerajinan tradisional suku Sasak.

Instrumen dalam penelitian ini terdiri dari instrument utama dan instrument pembantu. Instrumen utama dalam penelitian ini adalah peneliti sendiri (human instrument) dimana peneliti secara langsung terhubung dengan penelitian dan berperan sebagai pengumpul data dari hasil eksplorasi, wawancara, observasi, dan dokumentasi. Hal ini sejalan dengan yang dikatakan Denzin \& Lincoln (2009) yang mengatakan bahwa dalam penelitian kualitatif yang menjadi instrument utama adalah peneliti itu sendiri. Sedangkan instrument pembantu berupa pedoman wawancara yang terdiri beberapa butir pertanyaan. Setelah data diperoleh dianalaisis berdasarkan masing-masing pola unsur matematika yang ditemukan dan dikelompokkan berdasarkan kelompok pada kerajinan suku Sasak.

Teknik analisis data yang digunakan menggunakan triangulasi yaitu reduksi data, penyajian data dan penarikan kesimpulan. Reduksi data digunakan untuk menajamkan, menggolongkan, dan membuang data yang tidak diperlukan dalam penelitian. Data yang diperoleh dari hasil wawancara, observasi, dan dokumentasi direduksi dengan memilih informasi-informasi yang dibutuhkan sehingga memperoleh data yang valid. Berdasarkan hasil reduksi data diperoleh beberapa konsep matematika berupa unsur 
geometri yang terdapat pada kerajinan tradisional Sasak. Setelah melakukan reduksi data, tahap selanjutnya adalah penyajian data dimana peneliti menyajikan data yang diperoleh menggunakan gambar hasil dokumentasi, kemudian dari gambar dideskripsikan unsur-unsr matematika yang terdapat didalamnya. Kemudian pada tahap terakhir setelah melakukan reduksi dan penyajian data dilakukan penarikan kesimpulan untuk mengetahui apa saja unsur matematika berupa geometri yang terdapat pada kerajinan tradisonal Sasak.

\section{HASIL}

PENELITIAN

DAN

\section{PEMBAHASAN}

Berdasarkan hasil eksplorasi, observasi, dan dokumentasi, kerajinan tradisional yang memiliki konsep geometri. Dalam pembahasan ini disajikan bentuk geometri pada kerajinan tradisional Sasak sebagai berikut.

\section{Konsep Geometri pada Kerajinan Kain Tenun Sasak (Sesekan)}

Kerajinan kain tenun tradisional Sasak atau disebut dengan kain sesekan. Kain sesekan yang dijadikan sampel adalah kain sesekan dari desa Sade yang dibuat secara tradisional. Jika diperhatikan motif-motif kain tenun sesekan tersebut mengandung konsep matematis khususnya konsep geometri. Dengan adanya konsep geometri yang terdapat pada kain tenun sesekan ini, tanpa disadari bahwa nilai-nilai matematika sudah tertanam pada masyarakat pengrajin kain tenun sesekan Sasak.
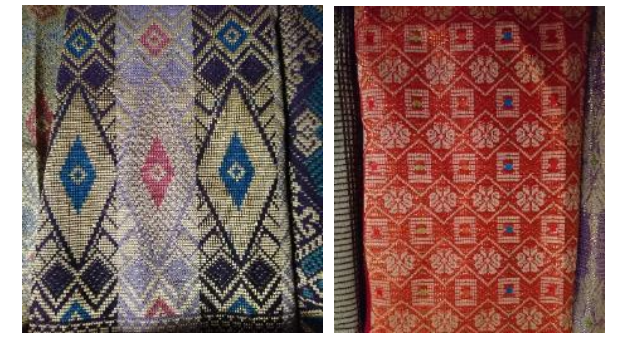

Gambar 1 Kain Tenun Sesekan

Contoh pola kain tenun sesekan masyarakat Sasak, Lombok, NTB dapat dilihat pada Gambar 1 di atas. Beberapa motif tersebut dapat dijadikan media pembelejaran di sekolah dasar untuk memperkanlkan konsep-konsep matematika khususnya pada bangun geometri sehingga mempermudah dalam memahami konsep matematika. Motif kain tenun sesekan di atas tersebut mengandung unsur geometri berupa bangun datar yaitu persegi panjang, segitiga, belah ketupat, jajargenjang, layang-layang, bahkan terdapat konsep sudut, dan kesebangunan.

\section{Konsep Geometri pada Kerajinan Anyaman Bambu}

Kerajinan tradisional dari anyaman bambu bukan sesuatu hal yang baru, tetapi merupakan budaya dari keterampilan masyarakat Sasak yang sudah diwariskan secara turun temurun. Kerajinan anyaman bambu 
yang dibuat oleh masyarakat Sasak sangat banyak sekali, mulai dari peralatan rumah tangga maupun hiasan-hiasan. Dalam penelitian ini akan dibahas konsep geometri yang terdapat pada kerajinan anyaman bambu berupa Nyiru, Tembolaq, dan Besek.

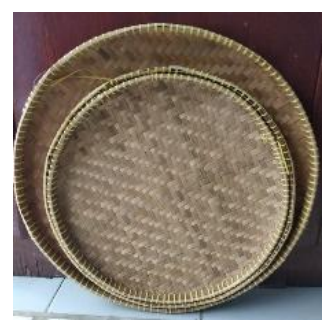

Gambar 2 Anyaman Bambu Nyiru

Gambar 2 di atas merupakan bagian dari kerajinan anyaman bambu yang di sebut dengan nyiru. Fungsi dari nyiru ini pada masyarakat Sasak digunakan untuk menampi beras agar antah dan beras terpisah, sehingga beras yang dihasilkan dapat dijual ataupun dimasak. Namun pada artikel ini yang menjadi fokus perhatian adalah bentuk dari nyiru tersebut. Jika diperhatikan bentuk kerajinan bambu nyiru tersebut mengandung unsur matematis yaitu konsep geometri pada bangun datar yaitu lingkaran. Pada umumnya bentuk dari nyiru tidak hanya berbentuk lingkaran melainkan ada yang berbentuk elips atau lonjong, tetapi bentuk nyiru pada masyarakat Sasak umumnya berbentuk lingkaran. Kerajinan nyiru ini bisa dijadikan media untuk belajar matematika pada tingkat sekolah dasar sehingga siswa sekolah dasar dapat belajar matematika dengan benda-benda nyata di sekitar mereka.

Kemudian kerajinan anyaman bambu berikutnya adalah Besek. Fungsi dari kerajinan besek ini bagi masyarakat Sasak adalah untuk menaruh/menyimpan barang-barang dan tempat makan. Namun sekarang besek sering digunakan untuk packing souvenir, cindramata, dan wadah untuk oleh-oleh, dan sebagainya. Gambar 3 berikut merupakan kerajinan besek bambu.

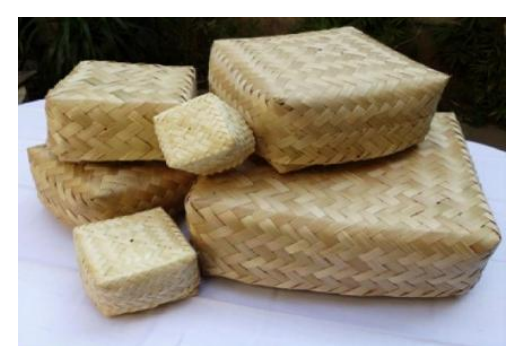

Gambar 3. Kerajinan Besek Bambu

Hasil dari eksploarasi pada kerajinan besek bambu adalah terdapatnya konsep bangun ruang. Jika diperhatikan kerajinan besek tersebut akan membentuk sebuah bangun ruang berbentuk balok dan kubus. Namun ditangan kreatif masyarakat Sasak, kerajinan besek bambu ini tidak hanya berbentuk balok dan kubus saja, tetapi banyak sekali bentuk besek yang bisa dikreasikan misalnya besek bambu dengan bentuk prisma. Selanjutnya adalah kerajinan tembolaq atau tudung saji yang merupakan kerajinan yang digunakan untuk menutup makanan. Tembolaq ini dibuat oleh masyarakat Sasak menggunakan 
anyaman bambu, dan bahkan ada yang menggunakan anyaman daun pandan. Berikut adalah gambar tembolaq.
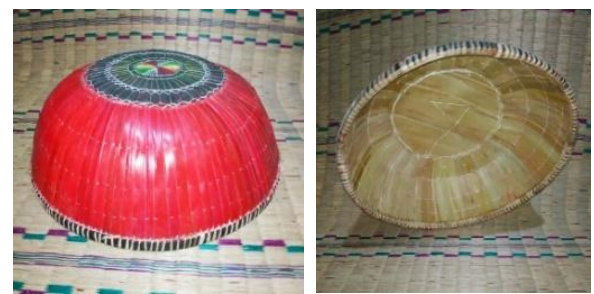

Gambar 4. Tembolaq (Tudung Saji)

Dari hasil eksplorasi dan pengamatan pada gambar tembolaq atau tudung saji di atas, dapat digali informasi bahwa konsep matematis yang terkandung di dalam kerajinan tersebut adalah konsep bangun ruang. Bentuk bangun ruang yang disajikan pada kerajinan tembolaq tersebut adalah setengah bola. Masyarakat Sasak mengkreasikan kerajinan tembolaq ini dengan berbagai macam ukuran diameter dan bentuk. Selain bentuk setengah lingkaran, pengrajin juga mengkreasikan bentuknya dengan bentuk setengah balok.

Agar lebih jelas hasil eksplorasi pada kerajinan tradisional suku Sasak, Lombok, NTB ini disajikan dalam tabel 1 berikut.

Tabel 1. Konsep Geometri dari Hasil Eksplorasi pada Kerajinan Tradisional Sasak

\begin{tabular}{|c|l|l|}
\hline No & Nama Kerajinan Tradisional & \multicolumn{1}{|c|}{ Konsep Geometri } \\
\hline 1. & Kain Tenun Sesekan & - Persegi \\
& & - Persegi Panjang \\
& & - Belah ketupat \\
& & - Jajargenjang \\
& & - Segitiga \\
& & - Layang-layang \\
& & - Konsep sudut \\
& & - Konsep kesebangunan \\
\hline 2. & Kerajinan Nyiru & - Lingkaran \\
& & - Elips/lonjong \\
\hline 3. & Kerajinan Besek Bambu & - Balok \\
& & - Kubus \\
\hline 4. & Kerajinan Tembolaq & - Prisma \\
\hline
\end{tabular}

Berdasarkan Tabel 1, konsep matematika yang terdapat pada kerajinan tradisional masyarakat Sasak dapat dimanfaatkan sebagai berikut:
Pertama dengan melakukan eksplorasi dari beberapa kerajinan tradisional Sasak yaitu pada kerajinan tenun sesekan dan kerajinan anyaman bambu didapatkan konsep geometri bangun datar dan bangun ruang. 
Dengan memberikan pemahaman konsep geometri dengan bendabenda konkret yang ada disekitar mereka akan lebih berguna daripada memberikan pemahaman siswa tentang konsep geometri secara langsung. Hal ini dikarenakan dalam mempelajari matematika, siswa sekolah dasar tentunya harus diberikan bentuk-bentuk konkret terlebih dahulu sebelum memahami bentuk yang lebih abstrak,. Apalagi siswa tingkat sekolah dasar menurut Piaget (Santrock, 2011: 45) masih berada fase operasional konkret, sehingga mereka akan lebih cepat memahami konsep geometri matematika apabila ada benda asli/konkret.

Kedua, melalui eksplorasi materi geometri dengan metode dan media pembelajaran dengan beberapa kerajinan tardisional Sasak, konsep materi matematika akan diterima lebih mudah dan bermakna bagi siswa (meaningful). Pengalaman belajar siswa lebih bermakna, dekat, kontekstual karena materi yang mereka pelajari ternyata dekat dengan mereka dan hampir setiap hari mereka temui. Bahkan ketika siswa mampu mengaitkan konsep materi matematika dengan pengalaman mereka, siswa akan dapat menemukan makna, dari makna inilah yang akan memberikan siswa alasan untuk terus belajar (Johnson, 2014:91). Dengan begitu diharapkan siswa sekolah dasar tidak lagi menganggap matematika itu sulit karena pada dasarnya, secara tidak disadari konsep matematis banyak sekali disekitar mereka. Dekat dan bahkan setiap hari siswa alami dan amati sediri. Siswa juga tidak lagi berfikir bahwa matematika itu hanya mempelajari angka-angka saja.

Dengan memperkenalkan kerajinan tradisional masyarakat Sasak sebagai media pembelajaran, secara tidak langsung siswa sekolah dasar diajarkan dan dibiasakan untuk mencintai produk budaya mereka sendiri.

\section{SIMPULAN}

Berdasarkan kajian terhadap bentuk kerajinan tradisional pada masyarakat Sasak diperoleh unsur etnomatematika yaitu konsep geometri berupa bangun datar dan bangun ruang. Kesimpulan yang didapatkan dari hasil eksplorasi adalah : 1) Konsep-konsep geometri yang terdapat pada motif kain tenun sesekan Sasak berupa bangun datar persegi, persegi panjang, belah ketupat, jajargenjang, segitiga, layang-layang, konsep sudut, dan konsep kesebangunan. 2) konsep geometri pada kerajinan anyaman bambu yaitu pada kerajinan nyiru terdapat konsep bangun ruang berupa lingkaran dan elips/lonjong, kemudian pada kerajinan besek bambu terdapat konsep bangun ruang balok, kubus, prisma, dan pada kerajinan tembolaq didapatkan bentuk setengah bola. 3) konsepkonsep matematika yang terdapat 
pada kerajinan tradisional Sasak dapat dijadikan media pembelajaran matematika yang lebih menarik sekaligus memperkenalkan matematika melalui budaya lokal mereka sendiri.

Saran dari hasil penelitian ini diharapakan agar menggunakan sampel kerajinan tradisional Sasak yang lebih banyak, sehingga dapat mengeksplorasi lebih dalam lagi konsep-konsep matematis yang terkandung didalamnya. Kemudian diharapkan ada penelitian lebih lanjut yang mengkaji tentang bagaimana penerapan proses pembelajaran berbasis etnomatematika atau pengembangan perangkat pembelajaran yang berbasis etnomatematika pada sekolah dasar.

\section{DAFTAR PUSTAKA}

Arwanto, A. (2017). Eksplorasi Etnomatematika Batik Trusmi Cirebon untuk Mengungkap Nilai Filosofi dan Konsep Matematis. Jurnal Pendidikan Mipa, 7(1), 40-49

Crawford Alan, Saul, E.W., Mathewa S., \& Makinster J. (2005). Teaching and learning strategies for the thinking classroom. New York: RWCT International Consortium.

D'Ambrosio, Ubiratan. (2001). Ethnomathematics Link Between Traditions and Moderenity. Rotterdam: Sense Publisher.

Denzin, N. K., \& Lincoln, Y. S. (2009). Handbook of Qualitative
Research. Jakarta: Pustaka Belajar.

Fauzi, A., \& Lu'luilmaknun, U. (2019). Etnomatematika Pada Permainan Dengklaq Sebagai Media Pembelajaran Matematika. AKSIOMA: Jurnal Program Studi Pendidikan Matematika, 8(3), 408-419.

Hardiarti, S. (2017). Etnomatematika: Aplikasi Bangun Datar Segiempat pada Candi Muaro Jambi. Jurnal Aksioma, 8(2), 99110.

Huda, N., T. (2018). Etnomatematika pada Bentuk Jajanan Pasar di Daerah Istimewa Yogyakarta. Jurnal Nasional Pendidikan Matematika, 2(2), 217-232.

Johnson, E. B. (2014). CTL, Contextual Teaching and Learning: menjadikan kegiatan belajarmengajar mengasyikan dan bermakna. Penerjemah: Ibnu Setiawan. Bandung: Kaifa.

Laurens, T. (2016) Analisis Etnomatematika dan Penerapannya dalam Meningkatkan Kualitas Pembelajaran. Jurnal LEMMA, 3(1), 86-96

Noto, M., S., Firmasari, S., Fatchurrohman, M. (2018). Etnomatematika pada sumur purbakala desa kaliwadas Cirebon dan kaitannya dengan pembelajaran matematika disekolah. Jurnal Riset Pendidikan Matematika, 5(2), 201-210

Rosa, Milton, \& Orey, D., C. (2011). Ethnomathematics: the cultural aspects of mathematics. Revista 
Lationamericana

de

Etnomatematica, 4(3), 32-54

Santrock, John. W. 2002. Live-Span

Development : Perkembangan

Masa Hidup, Edisi 5, Jilid I.

Jakarta : Erlangga.

Sirate, F. (2012). Implementasi etnomatematika dalam pembelajaran matematika pada jenjang pendidikan sekolah dasar. Lentera Pendidikan, 15(1), 41-54.

Ubayanti, S. U., Lumbantobing, H., \& Manurung, M. M. H. (2016). Eksplorasi etnomatematika pada Sero (Set Net): Budaya masyarakat Kokas Fakfak Papua Barat. Jurnal IImiah Matematika dan Pembelajarannya, 2(1), 1117.

Yazid, M. (2018). Eksplorasi Etnomatematika Masyarakat Suku Sasak Lombok Terhadap Penanaman Karakter Budaya. Jurnal Konseling Pendidikan, 2 (1), 22-32.

Zayyadi, M. (2017). Eksplorasi Etnomatematika pada Batik Madura. Jurnal Sigma, 2(2), 3540. 